\title{
Five-minute Fiction, and Other Ways to Mine New Markets
}

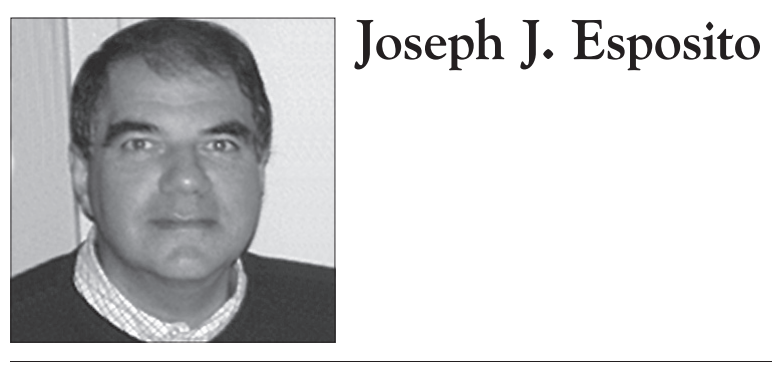

Joseph J. Esposito is CEO of GiantChair (giantchair. com), which provides direct marketing services to the publishing industry on the Internet. Previously the head of his own consultancy, the Portable CEO, specializing in all aspects and segments of publishing digital media, he has been an executive at Simon \& Schuster, Random House, and Merriam-Webster as well as at Encyclopaedia Britannica.

E-mail: espositoj@giantchair.com
To grow, publishers must either battle other publishers over market share or identify and serve new markets. Digital media are useful to publishers only insofar as they serve one of these aims. (A separate matter is using digital media to drive down costs and boost profits, but that is not growth in the defined sense.)

Using digital media to redistribute market share may be costly and not lead to the expected gains, as a publisher's rivals are likely to use the very same tactics: anyone can publish for the iPhone and Stanza, anyone can get books onto the Kindle or iPad. But with market share battles there is no relief; it is an arms race, and a publisher can no more forego publishing in digital form than it can stop seeking new and creative authors. For a publisher pursuing growth, alas, it's new markets or nothing.

Digital media do not necessarily lead to new markets, and in some situations digital media may actually serve to shrink markets. For consumer or trade publishing in the developed world, finding a new market can be challenging. Our lives are full, our calendars are snug, and our attention is spread over a seemingly infinite number of media choices, ranging from old-fashioned books to social networks, music, movies, museums, and countless other things. To find a new market here requires opening up a crack in a broad, seamless facade.

\section{Introducing the Interstitial Approach}

Which brings us to interstitial publishing, publishing between the cracks. (No, uh, wisecracks, please.) For a day filled with IMs and music and slathered over with email, one opportunity for publishers is to promote interstitial reading, reading that is done in the brief moments between other engagements, whether those claims on attention are other media or simply the wiggle room in a schedule: the time spent waiting for a plane, for a dentist, or for a meeting to begin. That's a 
huge number of minutes in any day; a good portion of our lives is wasted while we are waiting for the main course to arrive.

This point was brought to mind by a mailgroup post by O'Reilly's Andrew Savikas, who commented that he was stuck for an hour in an airport. What a great opportunity to pull out his iPhone and check out mail, alerts, and Web sites. But he could have been reading, if publishers had provided formal material (formal here means "the kind of stuff you are willing to pay for") to slip into the interstices of Andrew's day.

\section{Action in the Little Cracks}

An hour is a big crack in the day; to become a true interstitial publisher, you would have to aim smaller. How about the 10 -minute crack? Five minutes? Think of your own day: How often are you simply waiting, doing nothing? Daydreams don't count - because ultimately the aim of every media business is to colonize your mind's every moment. (Dust off that old copy of the science fiction classic The Space Merchants by Frederik Pohl and Cyril M. Kornbluth for a satiric vision of imperial marketing.)

If you had something to read that you could sip in draughts of five minutes at a time, or perhaps 10 , you would participate in the growth of the new market for interstitial publishing. And this is genuine growth, as at this moment total sales for books designed specifically for the interstices amount to zero or close to it. The goal is to go from zero to 60 in five minutes.

For interstitial publishing to work, you need a handy device (smartphone, or something like that), which you carry with you all the time so that you can take advantage of the cracks in the day. For this kind of thing, a Kindle or any dedicated ebook reader or even an iPad won't work, since it is an effort to pull such a device out of your bag as you wait in line in the supermarket.

So if it's growth you want (as distinct from market share), forget the Kindle and the iPad. A smartphone is a different matter, however: how many times do you see someone yank a BlackBerry from a belt clip and glance at incoming email? Instead of email, that could be the twenty-third chapter of your new micronovel. The proper device is critical, and the software that runs on it must have sophisticated bookmarking capabilities.

\section{Specially Crafted Content}

You also need (and this ultimately may be the harder part) content crafted with the interstices in mind. Reformatting Moby-Dick for interstitial publishing simply won't do, as the structure of the text, even the syntax of the sentences, militates against draughts of only five minutes. This is not a matter of immersive vs. non-immersive reading: it's entirely possible to get immersed in five minutes. But it is an issue of what you get immersed in. Sorry, Tolstoy and Grisham, even William Gibson, but we need a new breed of writer, who is born digital, who is born in the interstices.

Often interstitial publishing is confused with having a short attention span, as though a moment is somehow less valuable than an hour. The key to this new form of publishing, however, is that it views the short period of each entry not as a watered-down version of the "real thing," a long text, but as something built perfectly for the space and time it occupies.

This is what McLuhan meant by "understanding media": it's not about the content in itself but the content as it accommodates itself to the shape of the surface, which in turn is created and supported by the underlying technology.

Interstitial publishing can be fiction or nonfiction, but it is unlikely to be a single isolated fiveminute item, as it would be hard to market or to find such an item. More likely short items will be strung together in an anthology; the thesis of the anthology ("brief bursts about the new administration"; "101 short poems about transistors and current") will suffuse each item with a sense of being part of a whole.

Narratives for interstitial media may very well be linear within each five-minute episode, but it is improbable that item A will lead serially to item B, to item $\mathrm{C}$, and so forth. It would simply be hard to gather the narrative in our minds if it were written in this way. More likely each episode will have a beginning and an end - and then cut to another episode, which may be built around a different time or place or another character. All the pieces get assembled in our minds, five minutes at a time. 
For "five-minute fiction" to catch on, we will need creative people who probe the nature of the interstitial medium. It's easy to forget (or never to have known) that the linear narrative as we think of it today was in fact invented once upon a time when writers were first faced with books that were inexpensively manufactured and distributed to wide audiences.

Publishers will need to seek out writers who comprehend the new medium, who can engage a reader for five minutes, who can make the many pieces of the work congeal in the reader's mind. These writers will study readers, smartphones or related gadgets in hand, standing before the spinning dryer in the laundromat, stopped at a red light, preparing to board a plane, waiting for the meeting to begin. In all of this publishers will see growth.

The aim of digital media should not be (or should not only be) to substitute a screen for a printed page but to reinvent the text on the screen and, in so doing, to bring new readers into the marketplace. 